\title{
EL LIDERAZGO FACILITADOR DE JUAN FRANCISCO MEGINO EN EL "GRUPO INDEPENDIENTE POR ALMERIA" (GIAL)
}

THE FACILITATOR LEADERSHIP OF JUANFRANCISCO MEGINO IN "THE INDEPENDENT GROUP FOR ALMERIA" (GIAL)

\author{
Francisco Collado-Campaña \\ Universidad Pablo de Olavide \\ f_collado_c@hotmail.com \\ José-Francisco Jiménez-Díaz \\ Universidad Pablo de Olavide \\ josefco@upo.es
}

\begin{abstract}
Resumen
Las publicaciones sobre liderazgo político en Andalucía han destacado la investigación de dirigentes autonómicos y nacionales, pero existen pocos análisis de líderes en el ámbito municipal. Este artículo presenta un estudio de caso del líder Juan Francisco Megino, alcalde de la ciudad de Almería entre 1995 y 1999, que más tarde fundó su propio partido (Grupo Independiente por Almería, GIAL) para recuperar el poder local. Una vez expuestas las premisas de partida y el enfoque analítico, se contextualiza y se examina detalladamente la evolución del liderazgo de Megino. Entre los resultados destaca la dificultad para renovar el liderazgo en partidos políticos independientes de ámbito local y la intensa vinculación entre líder y partido.
\end{abstract}

Palabras clave: liderazgo político, politica local, sociología política, Almería, Juan Francisco Megino, GIAL.

\section{Abstract}

The publications on political leadership in Andalusia have highlighted the research of regional and national leaders, but there are few analyzes of leaders at the municipal level. This article presents a case study of the leader Juan Francisco Megino, mayor of the city of Almeria between 1995and 1999, wholatercreated his own party (Grupo Independiente por Almería, GIAL) to regain local power. Once the starting premises and the analytic approach have been disclosed, the evolution of Megino's leadership is contextualized and examined in detail. The results include the difficulty of renewing leadership in independent political parties of local scope, and the intense link between leader and party.

Keywords: political leadership, local politics, political sociology, Almeria, Juan Francisco Megino, GIAL. 


\section{Una introducción a los estudios sobre liderazgo local en España durante la democracia}

Los estudios sobre el poder local constituyen una encrucijada para politólogos, sociólogos, antropólogos e historiadores en España ${ }^{1}$. En cada territorio, región y municipio, la investigación sobre la estructura, el proceso y los resultados de la acción política se ha desarrollado a distintos ritmos según los intereses de los expertos, el acceso a las fuentes de información, el respaldo de otros agentes y las limitaciones temporales. Ello implica que no exista convergencia entre los actores, elementos y períodos analizados a nivel local y/o regional. En la Comunidad Autónoma de Andalucía se dispone de una abundante producción sobre el estudio de líderes políticos más recientes a nivel autonómico, pero no existe un conocimiento profundo basado en estudios de casos y análisis comparados sobre líderes políticos de ámbito municipal $^{2}$, especialmente para el período transcurrido desde la Transición hasta el presente. Esta laguna ${ }^{3}$ puede explicarse a partir de tres factores interrelacionados y cuyos efectos se combinan mutuamente entre sí. Primero, el abandono de los actores locales por parte de los politólogos. Como ya advirtió José María Maravall, hace más de tres décadas, fueron (y aún son) los historiadores locales quienes, con más frecuencia que los científicos políticos, se han ocupado del análisis de las élites y líderes individuales para profundizar en la comprensión, la interpretación y la contextualización política del momento presente en el entorno más cercano al ciudadano (Márquez, 1981). Segundo, la preeminencia de los enfoques colectivistas y cuantitativistas en la Ciencia Política en España frente a los análisis individualizados y más cualitativistas (Vanaclocha en Natera, 1999: 61). Y tercero, los consiguientes riesgos que implican el equívoco práctico y conceptual entre el científico y el político profesional cuando se aborda el estudio de un líder dentro de un contexto político, en el cual el investigador también puede ser un agente político. Tal situación plantea para el politólogo una confusión entre su función y responsabilidad como investigador y sus convicciones ideológicas personales (Jiménez-Díaz, 2018; Weber, 1993). En no pocas ocasiones, quienes investigan sobre liderazgo corren el riesgo de convertirse, bien en legitimadores de los actores estudiados, bien en detractores de estos.

Pese a esta laguna, existe cierta producción académica que permite conocer con detenimiento a los miembros de la élite municipal en el conjunto de la España democrática. Respecto a su perfil sociodemográfico y político, los regidores locales suelen ser hombres, de edad comprendida entre los 30 y 40 años, vinculados a la clase media y con mayor ambición política por parte de las mujeres que de los varones (Navarro y Sanz, 2018: 43). Los dos primeros rasgos se han mantenido constantes durante las primeras décadas de la democracia, siendo sólo los partidos de izquierdas, los que otorgaron mayor cabida a las mujeres (Capo, 1992). Desde la perspectiva de género, el liderazgo de las alcaldesas marca cierta distancia con el de sus homólogos masculinos, teniendo las primeras más preocupación por el

1 Los autores agradecen la labor de las evaluaciones anónimas que han permitido mejorar este artículo.

2 Desde este planteamiento, se considera como "líderes locales" a los alcaldes en tanto presidentes de los ayuntamientos que han conseguido a través del apoyo electoral y sus seguidores hacerse con dicha posición de poder. Un debate distinto es si el estilo de liderazgo corresponde más con el de un líder transformador o el de un gestor debido a que algunas teorías sólo consideran como líderes auténticos a aquellos que alteran y modifican las estructuras y el entorno en el que se sitúan (Blondel, 1987; Brown, 2018; Burns, 2010).

3 Dicha situación merecería de per se un artículo más extenso. No obstante, simplemente se presenta a modo orientativo para situar los estudios de casos sobre liderazgo local en Andalucía. 
contacto con los medios de comunicación, mayor dedicación en su desempeño, estilo cooperativo y tendencia al trabajo en equipo y la colaboración (Ruiloba, 2009 y 2017). Segundo, los alcaldes de las capitales de provincia y de los municipios urbanos suelen tener mayor formación universitaria en comparación con los del entorno rural (Natera, 1999: 359). En tercer lugar, la estructura política del sistema local se caracteriza por escasas competencias, reducido margen de maniobrabilidad para el alcalde y los concejales y comunicación fluida entre la élite local y la nacional (Bäck, Heinelt y Magnier, 2006: 22). Este diseño institucional favorece y está vinculado a las carreras políticas multinivel y verticales (Stolz, 2003); y el desarrollo de políticas intergubernamentales con la cooperación entre distintos niveles de gobierno. Cuarto, el líder municipal suele considerarse como el "presidente" en la ciudad para sus conciudadanos debido al poder simbólico que ostenta y la libertad que tiene para designar a los miembros de su equipo de gobierno (Magre y Bertrana, 2005; Navarro y Sanz, 2018). Dicho "presidente", en apariencia, es denostado en la práctica real por la limitación de sus competencias y la incapacidad financiera (Márquez, 2007). Quinto, los procesos electorales locales son considerados una competición de segundo orden (Reif y Schmitt, 1980 y 1997) y que se ve afectada por factores tales como el clima local (Botella, 1992), la personalización de las campañas electorales a través de los líderes nacionales (Martínez y Ortega, 2010), la nacionalización (Mabileau, 1972) y la estatalización de la política local (Collado-Campaña, 2017). Y sexto, desde la Transición hasta el presente, los miembros de la élite política han ido abandonando posiciones propias de una lógica gerencialista hacia otras más propias de políticos profesionales, responsables de mantener en marcha una iniciativa y/o política pública y con un alto grado de politización (Brugué, 2002).

La anterior caracterización de los primeros ediles permite conocer los rasgos y el entorno de los líderes locales en el contexto nacional de forma muy genérica. España tiene 8.124 municipios y Andalucía acoge a 778 de esas entidades locales en 2018, según el Instituto Nacional de Estadística (INE). La variedad de la casuística y de escenarios socio-económicos y político-institucionales dificultan el conocimiento y la comprensión en profundidad del liderazgo en un territorio concreto de dicha comunidad autónoma. Por lo tanto, los estudios de casos y el método comparado contribuyen a conocer con mayor profundidad cuestiones que de otro modo no podrían comprenderse, especialmente en casos o fenómenos poco frecuentes.

El presente artículo efectúa un análisis contextualizado y cualitativo del liderazgo político de Juan Francisco Megino López ${ }^{4}$. Este se desempeñó como alcalde del Partido Popular (PP) en la ciudad de Almería entre 1995 y 1999, pasando posteriormente a la oposición, después de ser derrotado por Santiago Martínez Cabrejas, dirigente del Partido Socialista Obrero Español (PSOE), que fue el primer alcalde electo tras la Transición. La negativa de Megino a dejar paso a otro candidato entre sus compañeros de filas -Luis Rogelio Rodríguez-Comendador- y su deseo de regresar a la presidencia del consistorio, le llevaron a fundar su propio partido político aprovechando su reconocido liderazgo entre ciertos sectores de la derecha y la sociedad civil almerienses. El Grupo Independiente por Almería (GIAL), liderado por él mismo, dividió electoralmente a los conservadores de la ciudad durante casi una década y hasta la retirada del líder de la vida institucional.

Así, con este estudio, se pretende responder a las siguientes preguntas:

4 El presente estudio de caso pertenece al conjunto de alcaldes andaluces entrevistados durante la realización de la Tesis doctoral del primer autor. El enfoque, la metodología y el análisis de los datos y discursos son resultado del trabajo entre los dos autores del artículo. 
- ¿Cómo fue el proceso de creación, construcción y pérdida del liderazgo político local de Megino?

- ¿Cómo han evolucionado las fuentes de poder y/o los apoyos al líder local desde sus inicios, su paso por la institución y su capitalización en su propio partido?

- ¿Cuál fue la naturaleza del partido GIAL y cómo evolucionó el proyecto creado en torno a la figura de Megino?

El presente análisis responde a una triple justificación académica, de capitalización política y empírica. En su vertiente académica, profundiza en un caso de estudio sobre un líder municipal del tiempo presente con un proyecto político independiente (partidos de ámbito local) en Almería ${ }^{5}$, completando los análisis cuantitativos que ya han realizado otros autores (Rahat y Kening, 2018; Ubasart, 2012). En su segunda justificación, el caso de Megino permite observar la capitalización política, por parte de un agente político, de determinados recursos políticos inicialmente pertenecientes a un partido atrápalo-todo (catch-all-party) como el Partido Popular, y posteriormente cooptados por su propio partido de corte personalista. Megino y su proyecto político del GIAL puede considerarse un caso minoritario al que merece dedicar un estudio concreto. Son tres las razones que lo configuran como un caso poco frecuente. Primero, el GIAL fue un partido político de ámbito local en una arena política municipal dominada por los partidos de ámbito estatal (Rahat y Kening, 2018). Segundo, en términos electorales, su presencia es asimétrica ya que sólo algunos partidos de ámbito municipal llegaron a representar el $9 \%$ del total de votos en algunas provincias en las elecciones municipales de 2011, mientras que en otras apenas han tenido presencia (Martínez, 2015). Además, el porcentaje de votos en el conjunto del espacio local español no ha alcanzado siquiera el $20 \%$ en ningún momento de la actual democracia (Ureta, 2018: 16). Tercero, una tipología propuesta para clasificar a estos partidos permitiría clasificar al GIAL como una formación de "lista independiente" al estar sostenida por un líder que rompió sus lazos con un partido de ámbito estatal, dotó a la misma de un alto grado de personalización y realizó un trabajo profundo con las redes de actores locales (Ureta, 2018: 13). Asimismo, se plantea la siguiente hipótesis: Megino ejerció el liderazgo público como un notable profesionalizado políticamente e incorporó el estilo de "jefe de la ciudad", durante su mandato como alcalde del Partido Popular en el Ayuntamiento de Almería; y, más tarde, se convirtió en un profesional integrado en la vida política local, creando su propio partido y tornándose en un líder "facilitador" (John y Cole, 1999) 6 que ocupó el poder municipal en coalición con el PP. Finalmente, en su dimensión empírica, se observa, en un nivel micro, cómo la actuación del líder estudiado tiene efectos considerables en distintas arenas políticas y un alcance macro-político.

\section{El enfoque socio-político y biográfico: una aproximación bio-histórica para diseccionar al sujeto político}

En el análisis del estilo de liderazgo local, la mayoría de los expertos consideran que deben tenerse en cuenta dos elementos como son: la capacidad de iniciativa política del alcalde y la base de poder que posee dentro de la ciudad (Brugué, 2002; Natera,

5 En un reciente estudio, se subraya la necesidad de completar el análisis cuantitativo de los partidos de ámbito local a través del estudio de casos concretos en los distintos territorios de España (Ureta, 2018: 17-18).

6 Los conceptos entrecomillados de esta frase se definen en el apartado siguiente. 
1999; John y Cole, 1999). Además, existen variadas clasificaciones de estilos de liderazgo local que se diferencian según el contexto cultural (europeo continental, anglosajón, etc.) y representan distintos tipos ideales de perfiles de gobernante (Yates, 1977; Flanagan, 2004). Sin duda, la creación del propio liderazgo se sostiene sobre el segundo elemento, puesto que posibilita que el líder pueda construirse y reafirmarse como una figura de referencia local (Magre y Bertrana, 2005). Ello lleva a distinguir entre el liderazgo político de los alcaldes y la existencia de otros líderes locales -como son los portavoces de grupos municipales, cabezas de lista y representantes de diversas entidades de la sociedad civil- en la arena política municipal. Estos últimos no han sido suficientemente abordados por los estudiosos de lo local debido a la preeminencia de los alcaldes como presidentes en la ciudad.

En este sentido, el presente artículo se fundamenta en la tipología de estilos de liderazgo local establecida por John y Cole (1999: 102), diferenciando entre los ediles que se anticipan a las necesidades de la comunidad (directives) y otros que se dedican a atender las demandas de los ciudadanos para ofrecer una respuesta posterior (responsive). De tal forma, dichos autores conciben a los alcaldes atendiendo a cuatro estilos de liderazgo, según el ejercicio que hacen de su poder en la ciudad, a saber. 1) Visionarios: con una actitud proactiva, predispuestos al cambio y con un liderazgo que se proyecta en el largo plazo, con capacidad para crear un grupo de seguidores y recabar apoyos fuertes, establecer políticas innovadoras y una coordinación efectiva respecto a la coalición y políticas. 2) Facilitadores: disponen de una agenda abierta, comparten su cuota de poder y aprovechan lo mejor de sus seguidores. Sin embargo, este tipo de líderes tienen grandes dificultades para proyectar su liderazgo y sus políticas municipales en el largo plazo, pues sus políticas dependen de las demandas de otros actores. 3) Jefes de la ciudad: disponen de una fuerte cuota de poder y escasa capacidad de anticipación, pero gozan de una fuerte determinación. Suelen usar la agenda local unilateral en la que apenas tienen cabida las demandas de terceros y coordinan sus políticas a través de su posición mayoritaria en el ayuntamiento. 4) Protectores: líderes sin una red de seguidores fuerte con grandes dificultades para producir el cambio. Por eso, su labor se dirige a mantener el statu quo, coordinar la acción municipal desde su despacho y presentan grandes limitaciones para compartir su poder (Collado-Campaña, 2018: 40; John y Cole, 1999: 102).

Como se ha mencionado en la introducción, es necesario distanciarse de los enfoques colectivistas y extremadamente macro-políticos para estudiar un caso minoritario de liderazgo local. En consecuencia, se ha recurrido a una perspectiva micro-política y micro-sociológica, así como a una metodología cualitativa e individualizada sobre el fenómeno estudiado. De hecho, las obras más sugerentes sobre liderazgo local están basadas en diversos estudios de casos que abordan a los líderes desde una perspectiva individualista en ciudades y/o regiones concretas (Briquet, 1997; Combes, 2018; Flanagan, 2004; Godmer y Marrel, 2017; Leland y Thurmaier, 2004; Mattina, 2016; Yates, 1977) ${ }^{7}$. Asimismo, se adopta el enfoque constructivista aplicado a los líderes, al ser una aproximación enfocada al propio sujeto que actúa como líder y siendo una respuesta reciente del post-positivismo (Elgie, 2015: 80). En consonancia

7 Estos autores hacen una apuesta por el estudio de caso para comprender el liderazgo, el clientelismo político, la vida cotidiana de los políticos profesionales, el éxito económico, el desarrollo demográfico, los riesgos medioambientales y otros fenómenos locales desde hace décadas. En España, los politólogos aún se muestran reticentes del análisis aislado de casos en la vida municipal, manteniéndose en el confort de los enfoques colectivistas acostumbrados a las macrocifras, las generalizaciones y el peligro de la falacia ecológica. 
con esta postura se han seleccionado técnicas que permitan adentrarse en la subjetividad del individuo. Por ello, se desarrolla el análisis historiográfico, la entrevista en profundidad y el relato biográfico aplicados a un estudio de caso concreto.

Desde la perspectiva teórica, se parte de la siguiente afirmación: el liderazgo local se concibe como una construcción social de carácter histórico y procesual. Ello implica las siguientes premisas analíticas en el estudio del líder local en un entorno democrático (Collado-Campaña, Jiménez-Díaz y Entrena-Durán, 2016). Primero, los líderes son agentes creadores de sentido que a través de la confección de una interpretación de su meta política (marco del objetivo político) atraen a sus seguidores y mediante sus acciones, pensamientos, ideas, esquemas de percepción y de clasificación de la realidad (habitus) establecen un orden político dirigido a lograr su objetivo. La capacidad del sujeto para moldear un orden y garantizar un equilibrio entre las condiciones simbólicas y objetivas de él mismo y otros actores involucrados permitirá clasificarlo como un líder con un carácter transformador o como un gestor. Generalmente, los desajustes entre las condiciones materiales y simbólicas afectan irremediablemente a la justificación de la posición de poder de un líder, abriendo posibles etapas de crisis, cambio y/o pérdida de autoridad. Segundo, el séquito compuesto por el líder, su equipo y seguidores se organiza en un espacio social jerárquico, junto con otros agentes (adversarios, colaboradores, etc.) cuyo centro de gravedad principal es la competencia por los recursos políticos; $y$, en distinto grado, esa competencia también implica la lucha por recursos de tipo económico, social, cultural, etc. (campo). Y tercero, la competencia del líder, sus seguidores y otros sujetos por esos bienes (capital político) marcan las dinámicas de poder que producen y reproducen el proceso de liderazgo (Joignant, 2012: 595). A su vez, la dinámica temporal del liderazgo puede subdividirse en varias etapas correspondientes con los determinados hitos logrados: la socialización política inicial, la legitimación del líder como alcalde y su continuidad en el tiempo como liderazgo institucionalizado.

En su vertiente metodológica, el análisis se centra en la aplicación de técnicas a dos objetos, los cuales se ponen en interrelación. En primer lugar, se efectúa una reconstrucción historiográfica del contexto ${ }^{8}$ del líder en la ciudad de Almería entre 1990 y 2011, coincidiendo con la etapa de vida pública de Juan Francisco Megino. Esta exposición subdivide el contexto en tres dimensiones para analizar los procesos de modernización y de cambio social, a saber: la dimensión socio-económica (grado de desarrollo económico, estructura social y sistema de producción), la dimensión político-institucional (estructuras, agentes y resultados inmersos en la normalización de la violencia política) y la dimensión simbólico-cultural (cultura, valores e identidades que legitiman el orden político-social) (Entrena-Durán, 2001: 261). En segundo lugar, se aplica una entrevista semi-estructurada y en profundidad al mismo líder local Juan Francisco Megino, y a Luis Rogelio Rodríguez-Comendador, quien fue tanto su adversario como alcalde entre 2003 y 2015. Estas entrevistas contrastan los conceptos teórico-empíricos definidos en el método adoptado para enfocar al líder político y se organizan comprendiendo la vida política como una experiencia biográfica que puede concebirse en las fases descritas en el párrafo anterior. Posteriormente, a partir de la información recabada se elabora un relato biográfico de Megino para responder a las preguntas de investigación planteadas. Tanto el proceso de contacto previo

8 Estudiar en profundidad el liderazgo político exige "situarlo en contexto" (Brown, 2018: 51) y conocer los cambios producidos en el mismo (Kellerman, 2012; Blondel, 1987; Blondel y Thiébault, 2010). Archie Brown sugiere cuatro "marcos de referencia interconectados" para el estudio del contexto de los líderes: "el histórico, el cultural, el psicológico y el institucional” (Brown, 2018: 51). 
como la realización de las entrevistas ${ }^{9}$ han contado con un cuaderno de campo como método de control, así como también el acceso al entrevistado se ha realizado a partir de porteros (gatekeepers) o de personas que han permitido contactar con los entrevistados.

\section{Almería en el contexto del cambio de siglo}

\subsection{Dimensión socio-económica}

Almería es el municipio más poblado de su provincia, contando con una densidad de población de 644 habitantes por kilómetro cuadrado en 2011. Este municipio experimentó un aumento demográfico de más de 35.000 habitantes durante dos décadas, pasando de 155.120 en 1991 a 190.349 en 2011 (Instituto de Estadística y Cartografía de Andalucía, 2018). En 2006, la cifra de inmigrantes en la ciudad de Almería era de 16.945 habitantes, la mayoría de los cuales -6.609 , es decir, un $39 \%$ - eran de origen marroquí y muchos de ellos estaban empleados en la agricultura local (Jiménez-Díaz, 2014: 69). Por su parte, la ciudad de Almería es el núcleo del área metropolitana almeriense y se torna en uno de los polos de la conurbación que incluye dicha área y las de El Ejido y Roquetas de Mar, a las que podrían sumarse los municipios de Vícar, La Mojonera y Enix. De hecho, el litoral almeriense presenta una considerable conurbación lineal como resultado del desarrollo económico acontecido durante la segunda mitad del siglo XX. Ello da cuenta del dinamismo socioeconómico del municipio de Almería cuya estructura económica está basada en varios sectores claves como son la agricultura familiar intensiva de invernadero y el amplio sector auxiliar de dicha agricultura ${ }^{10}$ (Entrena-Durán y Jiménez-Díaz, 2014; Jiménez-Díaz, 2014; Jiménez-Díaz, 2010). También es destacable la aportación del turismo local y del sector servicios asociado a este último (Aurioles y Manzanera, 2004).

Almería representa una de las provincias españolas con mayor capacidad económico-empresarial. Ello le ha llevado a ser calificada como un cluster e incluso un distrito agroindustrial, debido a la compleja red de productores agroalimentarios, empresas auxiliares y empresas de servicios en su provincia (Ferraro y Aznar, 2008: 378). Asimismo, se debe resaltar la aportación de la Universidad de Almería (UAL), que fue fundada en 1993. En el curso 2008/2009, la citada universidad contaba con alrededor de 12.612 estudiantes y con casi un millar de docentes ${ }^{11}$. El Parque Científico-Tecnológico de Almería (PITA), con sede en dicha Universidad, está configurado como centro de cooperación e innovación empresarial. Los principales objetivos del PITA son mantener relaciones operativas con universidades y centros de investigación, alentar el crecimiento de empresas basadas en el conocimiento y fomentar la innovación, sobre todo en el sector agroalimentario.

La estructura social de Almería dentro del conjunto andaluz queda definida por una mesocratización como fruto de la expansión de la educación y la salud públicas desde la década de los ochenta y la cual ha perdurado con distintos altibajos hasta el presente. Entre sus medios de promoción social se encuentran la herencia, la familia

9 Entrevistas realizadas por el primer autor del artículo durante el trabajo de campo emprendido en la ciudad de Almería entre los años 2014 y 2015.

10 El sector de agricultura intensiva almeriense es uno de los más importantes del mundo, habiéndose denominado como la "huerta de Europa" con miles de hectáreas de invernadero en la costa del Poniente, Campo de Dalías y Campo de Níjar, comarcas que emplean a miles de agricultores familiares e inmigrantes de diversas nacionalidades.

11 Fuente: https://w3.ual.es/conocenos/cifras-alumnos.html (Consulta realizada: 10/4/2019). 
y las redes sociales; siendo las redes primarias las que favorecen la integración en la sociedad (Camarero, 2009: 108). En el ámbito de la agricultura local, la herencia representa aún un mecanismo de transmisión de recursos de una generación a otra entre los agricultores familiares (Jiménez-Díaz, 2010: 127). Algunos autores coinciden en señalar que la sociedad almeriense -y en general Andalucía Oriental- presenta diferencias importantes con otras estructuras debido al predominio del minifundismo y la pervivencia del pequeño y mediano propietario agrícola. Evidentemente, ello tiene consecuencias directas en los estilos de vida, actitudes y valores de los almerienses (Cazorla y Delgado, 1993).

\subsection{Dimensión político-institucional}

En lo referente a la dimensión político institucional de Almería, ésta muestra un dinamismo moderado que se refleja en sus cuatro alcaldes para el período 1991-2011 (ver Tabla I). Los distintos regidores se han alternado de forma paulatina, entre los dos principales partidos de la arena nacional, PSOE y PP. Lo que impide calificar al consistorio almeriense como una institución estable en términos de continuidad de sus alcaldes. Asimismo, cabe mencionar la alcaldía de Santiago Martínez Cabrejas (PSOE), que representa la segunda etapa de su vida política, ya que anteriormente fue el primer alcalde tras la dictadura, entre 1979-1991 (Fernández, 2014). Y también, las sucesivas investiduras de Luis Rogelio Rodríguez-Comendador hasta 2011, en las que necesitó del apoyo del GIAL de Juan Francisco Megino para poder formar gobierno.

Tabla I. Alcaldes de Almería: votos y concejales entre 1991-2015

\begin{tabular}{|c|c|c|c|c|c|}
\hline Fecha & Alcalde & Votos (\%) & Votos (N) & Ediles & Elección \\
\hline 1991 & Fernando Martínez López (PSOE) & 40,43 & 24.796 & 12 & um \\
\hline 1995 & Juan Francisco Megino López (PP) & 48,81 & 40.530 & 14 & uma \\
\hline 1999 & Santiago Martínez Cabrejas (PSOE) & 40,26 & 30.932 & 12 & cvm \\
\hline 2003 & $\begin{array}{c}\text { Luis Rogelio Rodríguez-Comendador } \\
\text { (PP) }\end{array}$ & 38,36 & 31.461 & 11 & cvm \\
\hline 2007 & $\begin{array}{c}\text { Luis Rogelio Rodríguez-Comendador } \\
\text { (PP) }\end{array}$ & 45,52 & 32.725 & 13 & cvm \\
\hline 2011 & $\begin{array}{c}\text { Luis Rogelio Rodríguez-Comendador } \\
\text { (PP) }\end{array}$ & 58,5 & 44.785 & 18 & uma \\
\hline
\end{tabular}

Fuente: Elaboración de Collado-Campaña (2018) a partir de Ministerio de Interior. Elección: uma = unipartidista con mayoría absoluta, um = unipartidista en minoría o mayoría simple, cvm = coalición vencedora mínima, $\mathrm{cs}=$ coalición sobredimensionada, $\mathrm{cm}$ = coalición minoritaria (Márquez, 2007:

316).

En lo que concierne al liderazgo de los alcaldes almerienses, se ha demostrado que sus carreras políticas están influidas determinantemente por conflictos locales y pugnas entre el grupo municipal y su respectiva estructura orgánica. De hecho, una confrontación de este tipo es la que llevó a Megino a fundar el GIAL en un intento de mantener su carrera política horizontal y/o municipalista. Su victoria política en las elecciones locales de 1995 representa el segundo apoyo porcentual en votos de los líderes expuestos en la anterior tabla, sólo superado por Luis Rogelio RodríguezComendador en la convocatoria de 2011, una vez el GIAL había desaparecido.

La cantidad de grupos municipales en el pleno han oscilado entre los tres y cuatro (Tabla II). Aunque el caso de Megino pueda ser calificado como poco habitual y/o 
escaso, la arena local está claramente definida por los clásicos fenómenos de estatalización de la política local (al estar representados los partidos atrápalo-todo de la política nacional), y de nacionalización de la vida local (al verse afectados los cambios de alcalde por los cambios de ciclo político en el ejecutivo central). Las coaliciones que se observan se corresponden con bloques ideológicos claramente definidos. De este modo, la mayoría de los alcaldes de izquierda han precisado del apoyo de otros grupos de su ámbito ideológico; este mismo fenómeno se reprodujo para la derecha durante la etapa en que estuvo fracturada debido a la disputa entre PP y GIAL, quienes se vieron obligados por la fuerza de las circunstancias a cooperar mutuamente. De hecho, se observa que tras la desaparición del GIAL se produce una considerable recuperación de concejales (y de votos) para los populares en las elecciones de 2011. Ello, sin duda, nos lleva a enfatizar la diferenciación entre la derecha política y la derecha de la sociedad civil, las cuales no siempre se corresponden estrictamente en términos demoscópicos.

Tabla II. Tamaño de grupos municipales (número de concejales) en Almería entre 1991-2015

\begin{tabular}{|c|c|c|c|c|c|c|}
\cline { 2 - 7 } \multicolumn{1}{c|}{} & 1991 & 1995 & 1999 & 2003 & 2007 & 2011 \\
\hline PSOE & 12 & 9 & 12 & 10 & 11 & 7 \\
\hline PP & 10 & 14 & 13 & 11 & 13 & 18 \\
\hline IU & 3 & 4 & 2 & 1 & 1 & 2 \\
\hline PA & 2 & 0 & 0 & 0 & 0 & 0 \\
\hline GIAL & 0 & 0 & 0 & 5 & 2 & 0 \\
\hline
\end{tabular}

Fuente: Elaboración de Collado-Campaña (2018) a partir de Ministerio de Interior.

\subsection{Dimensión simbólico-cultural}

La provincia de Almería goza de una población con un alto porcentaje de sujetos con formación básica como resultado de la expansión del Estado del bienestar y los servicios educativos (INE, 2011a). Desde 1990 hasta 2010, se redujo la cuota de personas sin una educación escolar mínima en casi la mitad, representando en torno a un $16 \%$ sobre el total para ese último año. Mientras que el sector de individuos con una formación superior ha pasado del 9 al 15\% en ese mismo período. Este aumento de los niveles de cualificación de la sociedad almeriense repercute, previsiblemente, en una ampliación de las expectativas cívicas y de las actitudes críticas, observándose en este caso un proceso de cambio cultural y de incremento de la capacidad cognitiva, particularmente entre los más jóvenes de dicha sociedad, en el sentido otorgado por Inglehart (2001) a tal proceso.

Desde el punto de vista cultural, se debe mencionar sus bajas tasas en producción editorial y audiencia en la gran pantalla en comparación con otras provincias andaluzas (INE, 2011b). Ello es debido principalmente a la dispersión y el reducido tamaño de sus principales núcleos urbanos y, así, puede ponerse en relación con sus equipamientos culturales en cine, bibliotecas, etc. En cambio, sí destaca por la presencia de una cantidad considerable de equipamientos hosteleros siendo de un $57 \%$ sus plazas en alojamientos por cada 1.000 habitantes para 2010 y sólo siendo superado por Málaga. Esto dibuja una panorámica en la que el almeriense no destaca tanto por ser un consumidor cultural -en comparación con otras zonas de Andalucía-, pero sí por representar un importante oferente. De ahí que su cultura esté enfocada a ser un destino turístico por sus parajes naturales y costas, lo que se intentó potenciar desde 
el Ayuntamiento de Almería a través de la celebración de los Juegos Olímpicos del Mediterráneo.

Por último, respecto a la identidad territorial, la mayoría de los andaluces tienen un sentimiento equilibrado entre la pertenencia a su región y a su país (Aguiar y Espinosa, 2011; Coller, 2014). En el caso que nos atañe, cabe destacar que la provincia de Almería representó un territorio disonante durante la constitución de Andalucía como comunidad autónoma. Durante el referéndum para la aplicación de la llamada "vía rápida" al territorio andaluz para convertirse en una entidad autonómica, la votación en Almería no alcanzó las cifras estipuladas. Lo cual produjo una posterior modificación de la legislación para que se pudiese introducir a esta provincia en la futura Comunidad de Andalucía ${ }^{12}$. Esta situación, junto con la singularidad de su estructura socio-económica, ha planteado diferentes dudas sobre el sentimiento regionalista de la sociedad almeriense para el conjunto andaluz. Este fenómeno es, al mismo tiempo, tanto un recurso como un problema para los políticos y/o líderes autonómicos cuando basan sus estrategias en el encuadramiento de sus seguidores y votantes en torno a identidades regionales y/o locales.

\section{El liderazgo de Juan Francisco Megino: de alcalde popular a liderar su propio partido}

\subsection{Socialización política}

Desde la perspectiva biográfica y secuencial del liderazgo, los orígenes de Juan Francisco Megino López se remontan hasta la localidad jienense de Navas de San Juan, situada en la comarca del Condado. Allí nació en el seno de una familia de clase media en 1944. Su padre era un funcionario del consistorio del pueblo y su madre se encargaba de las labores de la casa. De esta forma, estudió gracias al esfuerzo de su hogar. Durante su infancia y juventud, creció en un ambiente familiar definido por una ideología liberal-conservadora y cercana a los postulados cristianos. Según él mismo, no existía una preocupación política previa, pero sí una vocación de servicio público especialmente en el ámbito de la salud y de lo social. Sintió su vocación por la carrera médica, desde la niñez, sin que existiera un antecedente de otro profesional sanitario en su familia más cercana.

"Mi vocación por la Medicina es absolutamente temprana, de tal manera, tan temprana que tenía diez años cuando estaba estudiando primero de bachillerato, yo ya quería ser médico. Y no tengo ningún antecedente familiar ni en la medicina ni en la farmacia ni en veterinaria ni en practicante. Nada, pero mi voluntad de ser médico y lo conseguí pues yo diría de un modo bastante brillante. No tenía más objetivo que estar formándome en una familia además modesta que tuvo que hacer su esfuerzo (Fuente: Entrevista a Juan Francisco Megino)". Fuente: entrevista a Megino.

Cuando acabó sus estudios básicos, Juan Megino cursó la Licenciatura en Medicina en la Universidad de Granada. Durante esos años estudió a través de las becas que concedía el Ayuntamiento de Navas de San Juan, que exigían unas calificaciones altas para disfrutarlas, según sostiene. Atraído por la participación en el ámbito de sus estudios, Megino fue delegado de curso y de la Facultad de Medicina. Al terminar realizó la especialidad en Urología y comenzó trabajando como cirujano en el

12 Para más información puede leerse la siguiente noticia en El Ideal (consulta realizada 10/4/2019): https://www.ideal.es/almeria/201610/12/cuando-estado-cambio-para-20161012003232-v.html 
Hospital de Torrecárdenas en Almería en torno a 1973. Una vez establecido en la ciudad almeriense se dedicó en exclusiva a su carrera médica, aunque ya existía una preocupación previa por la participación en política.Como resultado de su inquietud profesional fundó el Sindicato Profesional de Médicos. A raíz de esta experiencia, Megino fue consciente tanto de su inquietud de servicio público como de su deseo por participar en la vida política. No obstante, una máxima que ha estado presente a lo largo de su vida es la persistencia y el deseo de continuar en su profesión como médico, inclusive durante aquellos años que hubo ejercido como representante político.

"De ahí, un salto desde esa inquietud, de dar un salto a la política sólo dependía de que alguien me diera la oportunidad. Insisto, me la dieron en el Ayuntamiento. Igual me lo hubieran dado para la Junta o no sé si al Senado o al Congreso de los Diputados. Yo hice lo de, lo del Ayuntamiento por la sencilla razón de que yo siempre he querido compatibilizar la Medicina con el desarrollo de esa actividad pública. Evidentemente en otra administración no lo hubiera podido hacer". Fuente: entrevista a Megino.

Juan Francisco Megino tenía un pensamiento y una acción política caracterizada por la competitividad, un importante sentido y significado que otorgaba a su profesión como médico, una ideología conservadora católica y una vocación de servicio público. De su participación en el campo médico, contaba con una trayectoria consolidada como médico; y de su implicación en el campo sindical y corporativo, fundador y miembro del Sindicato Profesional de Médicos, llegando a ostentar una vocalía en el Colegio de Médicos. Además, en el campo de la representación universitaria había adquirido cierta experiencia dentro de la Facultad de Medicina de la Universidad de Granada. Sin embargo, Megino no tenía una experiencia política ni una afiliación partidista previas, lo que compensaba con un deseo de participar en la vida pública. Por tanto, no era un político profesional al uso, sino un profesional sanitario iniciado en la política.

\subsection{Legitimación}

A principios de los noventa, Megino se acercó a los postulados del Partido Popular en consonancia con su ideología liberal-conservadora. En las elecciones locales de 1991 , se convirtió en concejal en la oposición como número cuatro e independiente ${ }^{13}$ por invitación directa del portavoz Fernando Cabezón ${ }^{14}$ y con quien mantenía una amistad $^{15}$, durante la alcaldía de Fernando Martínez. A lo largo de este mandato, adquirió un conocimiento de los problemas de la agenda local como edil y al final de dicho período fue seleccionado para encabezar la lista en la siguiente convocatoria. A partir de aquí, Megino ya contaba con una serie de recursos como la experiencia y la formación adquirida dentro del Ayuntamiento.

13 Después de obtener su acta como concejal, Megino se integró como militante en el PP.

14 Previamente, Fernando Cabezón había sido candidato a alcalde por el Centro Democrático y Social (CDS) en 1987 y era ingeniero en la Diputación Provincial de Almería en excedencia. Tras el giro socialdemócrata de Suárez, abandonó la formación centrista y se pasó al Partido Popular, donde fue elegido como candidato a la alcaldía en los comicios de 1991 a través de una encuesta telefónica. Este dato está disponible en un perfil de alcaldables de ABC (consulta realizada 10/4/2019): http://hemeroteca.sevilla.abc.es/nav/Navigate.exe/hemeroteca/sevilla/abc. sevilla/1991/05/14/043.html

15 Para más información acceder a la siguiente noticia (consulta realizada 10/4/2019: https://elpais. com/diario/2003/05/11/andalucia/1052605340_850215.html 
"Yo creo que fue una etapa muy formativa y en ese sentido, sí que se puede decir que los ayuntamientos son una escuela de formación política. Y ahora se ve digamos con mayor, eh, digamos "descaro" la cantidad de gente que aspira a altísimos cargos sin haber pasado siquiera por esa escuela de, de gestión política que son los ayuntamientos. A mí me sirvieron esos cuatro años fundamentalmente de aprendizaje, mucho, pues para eso tuve gente al lado que me orientaban y desde el conocimiento de esa realidad". Fuente: entrevista a Megino.

En la campaña de los comicios municipales de 1995, Juan Francisco Megino se presentó como cabeza de lista por su partido. A partir de aquí comenzaba su legitimación como nuevo líder del PP en el consistorio de Almería. En este momento, el alcalde socialista, Fernando Martínez, había mantenido bajo control la situación ante la posible victoria que podría haber obtenido el PP en las elecciones anteriores. Pese a ello, los distintos escándalos de corrupción que afectaban al PSOE a nivel nacional ofrecían un riesgo de pérdida de votos, lo que beneficiaba a Izquierda Unida (IU) que podía crecer en el consistorio a partir de dichos votantes de izquierda, produciéndose un clásico fenómeno de nacionalización de la política local. Ante este contexto, el candidato popular debía desarrollar una campaña que le permitiera lograr una mayoría absoluta en lo que parecía ser una ventana de oportunidad para su victoria.

En esta situación, Megino centró su visión y discurso político en la deuda acumulada por el consistorio durante la alcaldía de Martínez López y la necesidad de más infraestructuras y equipamientos para el municipio. Asimismo, otro elemento integrante del mensaje de este alcalde, y en correspondencia con sus ideas, fue la promesa de continuar con su labor como médico en caso de ser elegido como alcalde. Así, una de las tácticas de la campaña de Juan Francisco Megino residía en presentar su figura como un representante político separado de lo que se denomina la "empresa política como profesión" (Weber, 1993: 151) o profesionalización de la política. De esta forma, creaba una dicotomía entre un extremo donde se situaría el ciudadano ajeno a la vida política profesionalizada y otro donde se situaban la política profesional que se correspondería con sus adversarios políticos dentro de su discurso. Así, se mostraba como representante del ciudadano de a pie.

"En la campaña del noventa y cinco, yo dije a los ciudadanos que si resultaba elegido yo iba a seguir ejerciendo como médico. Eso fue muy criticado por los grupos que opositaban contra el Partido Popular entonces, pero yo lo dejé bien claro, yo quería compatibilizar la medicina con la política porque tengo un sentido de la política no, no profesional. Es una actividad nobilísima, pero que no puede conllevar que tú abandones tu actividad profesional en aras a ese, a ese objetivo". Fuente: entrevista a Megino.

Finalmente, su figura como político "no profesional" y el efecto de la nacionalización de la vida local en un momento bastante nefasto para los socialistas en el nivel nacional, Juan Francisco Megino obtuvo una victoria con una mayoría absoluta de 14 concejales. Por su parte, el PSOE consiguió 9 e IU aumentó hasta 4 ediles su representación en el consistorio, siendo expulsados los andalucistas que hasta ese momento se debatían en las luchas internas

"Entonces sin esa mayoría absoluta, digamos, se pierde mucho tiempo discutiendo. Y en aquella situación, insisto, donde había que tomar medidas muy duras, muy duras de, de actuación era más necesario que nunca esa mayoría absoluta. Yo la primera medida que, que, que puse una vez conocida la realidad del Ayuntamiento, que de alguna manera yo lo conocía porque había estado cuatro años en la oposición, pero no es lo mismo que enfrentarte a la realidad. Lo primero que 
hice fue reunirme con los partidos políticos representados en el Ayuntamiento". Fuente: entrevista a Megino.

Tras esta victoria, se fortalecía la legitimación como líder de Megino y la cerraba al convertirse en el primer alcalde de derechas tras la Transición en Almería. Entre las distintas actuaciones que realizó el nuevo alcalde cabe destacar la puesta en marcha de un plan de saneamiento económico del consistorio con un plazo de dos años y con el objetivo de equilibrar la balanza de gastos. Además, Megino continuó con la finalización de las últimas fases de la Rambla de Almería que ya habían iniciado y desarrollado sus antecesores. Durante sus primeros años de mandato, Megino se apoyó principalmente en las áreas de urbanismo y hacienda, adoptando el mencionado estilo de "jefe de la ciudad". Ello se explica principalmente debido a la situación de crisis en la que se encontraba el Ayuntamiento, según sostiene el entrevistado, y a las distintas obras de actualización que exigía la ciudad. Así con todo, fueron áreas claves para mejorar las cuentas públicas del consistorio, consiguiendo sus objetivos principales conforme fue finalizando el mandato.

Pese a ello, el líder local consideraba que los Juegos Olímpicos de Barcelona y la Exposición Universal de 1992 habían permitido desarrollar la ciudad como capital de provincias periférica. Por lo tanto, un evento que emplease Almería como sede permitiría situarla tanto en su dimensión provincial como en el ámbito nacional e internacional. Ante esta situación, Juan Megino retomó un proyecto que ya había planteado anteriormente un concejal popular en la década los ochenta. Por eso, al alcalde propuso convertir a Almería en sede de los Juegos Olímpicos del Mediterráneo y aprovechar este evento para aumentar las infraestructuras deportivas del municipio.

"Hay una anécdota que aquí la conoce perfectamente la gente, es que esa, esa moción sale de una conversación, de una conversación, de entre un periodista del diario Ideal y un concejal del Partido Popular. El momento de que se hablaba de qué podía hacer Almería para conseguir, digamos, algún beneficio en relación con los grandes eventos del año noventa y dos [...] En un bar próximo al Ayuntamiento, un periodista y un concejal estuvieron maquinando y pensaron, bueno, pues eso prosperó y a partir de ahí hubo una voluntad unívoca". Fuente: entrevista a Megino.

Siguiendo esta lógica, el alcalde dispuso una serie de actuaciones para garantizar la victoria de la candidatura de Almería en los Juegos Olímpicos. Dentro de su gestión, había comenzado una nueva línea del Plan General de Ordenación Urbana (PGOU) a principios de su mandato y que fue aprobado en 1998. Este plan urbano contemplaba una serie de suelos para los posibles equipamientos que pudiera precisar la ciudad en caso de ser elegida para la celebración de este evento. En el plano nacional y autonómico, el alcalde consiguió el apoyo y el respaldo de las diferentes instancias de gobierno para presentar la candidatura de Almería. En su entorno más cercano, incluyó y recabó el apoyo de otros seis municipios colindantes como El Ejido, Vícar, Huércal, Gádor y Cuevas del Almanzora que serían consideradas como subsedes. Por lo que, esta gran actuación también suponía unas exigencias de desarrollo de infraestructuras, transportes y comunicaciones para otras localidades aledañas, convirtiendo un proyecto de desarrollo local en una mejora de alcance supramunicipal. Finalmente, la candidatura almeriense, que competía incluso con ciudades que eran capitales de Estado, fue seleccionada por el Comité Internacional de los Juegos Olímpicos del Mediterráneo ${ }^{16}$ en 1999.

16 Para más información se puede acceder a la página oficial de esta edición de los Juegos Mediterráneos (consulta realizada 10/4/2019): http://almeria2005.coe.es/. 
En las elecciones locales de 1999, el marco primario de la campaña de Juan Francisco Megino se fundamentó en la gestión económica realizada en las cuentas municipales y especialmente en el proyecto de los Juegos Olímpicos del Mediterráneo. Sin embargo, el regreso de Santiago Martínez Cabrejas como candidato por el PSOE planteaba un nuevo horizonte al alcalde popular. El veterano alcalde socialista de los ochenta acabó truncando las aspiraciones ${ }^{17}$ de Megino. Tras los comicios, la suma de ediles del grupo socialista (12 concejales) y de Izquierda Unida (2 concejales) era mayor que los concejales obtenidos por el Partido Popular que había obtenido 13 y, por tanto, había perdido su mayoría absoluta. De esta forma, Santiago Martínez volvió a ser nombrado alcalde en su cuarto y último mandato, responsabilizándose del inicio de las actuaciones correspondientes para la adaptación de la ciudad a un evento deportivo de envergadura internacional. Mientras tanto, como apunta RodríguezComendador, se abría una ventana de oportunidad para la renovación del portavoz y líder municipal de los populares a través de su candidatura. Ello se fue fraguando a lo largo de esta corporación municipal, en la que se empezaba a producir un divorcio entre el líder y la propia estructura partidista, que tendría graves consecuencias en el futuro.

"Gana las elecciones, pero se queda en trece con tan mala suerte de que, claro, PSOE e Izquierda Unida suman mayoría absoluta. Entonces, pues descabalgan la candidatura de Juan Megino. Entonces lo que pasa durante ese tiempo es que desde el partido se ve conveniente que Juan Megino pues vaya a otro sitio y que haya una oportunidad por una persona distinta". Fuente: entrevista a Rodríguez-Comendador.

\subsection{Fractura del liderazgo político local y creación del GIAL}

En el período entre 1999 y 2003, Juan Megino se mantuvo como líder de la oposición y enfocado a nivel personal y político en el evento deportivo de los Juegos Mediterráneos. A comienzos de verano de 2002, el Partido Popular le informó que Luis Rogelio Rodríguez-Comendador sería el nuevo candidato para los comicios locales de 2003 y que él sería trasladado como candidato para las elecciones generales. Esta decisión supuso un importante golpe para el líder popular. Sus ideas políticas se habían reafirmado en el deseo de continuar con su profesión como médico en Almería y una vocación municipal que había desarrollado desde sus comienzos como concejal. Además, su abandono como candidato local suponía una ruptura de su posición dominante en el campo político interno del PP en el consistorio. Megino se encontraba en una situación crítica producida por su rechazo a cambiar un habitus que ya había construido tras más de una década dentro de la institución municipal. Finalmente, rechazó la oferta de iniciar una carrera política multinivel y abandonó el Partido Popular antes de las siguientes elecciones locales.

"Me marché y formalmente dejé, me di de baja del partido y me volví a mi actividad profesional en el hospital público... y conmigo se fueron unos cuantos concejales que entendían que no se había hecho justicia conmigo. ¿Qué sucede? Pues que estando yo, desde ese animal político que siempre he sido, cuando ya vuelvo a mi actividad profesional, hubo mucha gente que recordaba mi tránsito por el Ayuntamiento y me invitaban a volver a él". Fuente: entrevista a Megino.

17 En la práctica, los proyectos planteados por Megino siguieron adelante, tanto la sede de Almería para los Juegos Mediterráneos como los equipamientos necesarios. Esto fue debido entre otras cosas a la reputación y el capital social del que gozaba Santiago Martínez en el mundo del deporte local. 
La reputación y la personalización política de Megino habían repercutido intensamente entre el equipo de concejales del PP en el Ayuntamiento. Su salida política provocó que sus más firmes seguidores también abandonasen el partido, creando una importante fractura entre los populares tanto a nivel local como provincial. De hecho, el nuevo candidato, Rodríguez-Comendador, se enfrentaba a una situación complicada ya que esta crisis interna suponía una pérdida de la estructura interna del PP y de votos, como después se comprobó. Aunque el GIAL, no dejaba de ser un proyecto independiente fundado por un notable local, sus recursos, seguidores y votantes habían sido anteriormente los de los populares almerienses, produciéndose una cooptación de dichos elementos a partir de su capital político. Así lo atestigua, Luis Rogelio Rodríguez-Comendador, en su entrevista.

"Se había producido una escisión en el partido porque Juan Megino en su momento, cuando le anuncian que no va a ser candidato decide romper el grupo y se va, se va fuera del Ayuntamiento y decide concurrir a las elecciones con un partido independiente. Eso provoca lógicamente una situación muy nueva, muy distinta porque al final son astillas de la misma madera de las que estamos hablando. Eran gente del PP que se involucran en un proyecto independiente. Entonces evidentemente las elecciones son muy difíciles". Fuente: entrevista a Rodríguez-Comendador.

Ante este nuevo horizonte, Juan Francisco Megino no se resignó a abandonar la política local y, apoyado por sus colaboradores, creó un nuevo partido político en un plazo de seis meses. A finales del 2002, surgió el Grupo Independiente por Almería (GIAL): partido de ideología conservadora y centrado en el ámbito almeriense que él mismo lideraba y que se había nutrido con antiguos elementos del Partido Popular. Mientras tanto, el candidato principal de la derecha almeriense, RodríguezComendador, se dedicó a realizar una campaña electoral para aumentar su grado de conocimiento entre los ciudadanos, ya que procedía de la Diputación Provincial. Como señala él mismo, fue una "campaña de desgaste". Tras el recuento de los resultados en las elecciones locales de 2003, el líder de esta nueva formación de derechas anunció que el partido se presentaría en toda la provincia de Almería. En las elecciones de 2003, la candidatura de Megino (GIAL) para el ayuntamiento almeriense obtuvo 5 concejales y la encabezada por Rodríguez-Comendador por el PP, conseguía 10 ediles. Entre los partidos de la izquierda, el PSOE obtenía 10 e Izquierda Unida un único concejal. De este modo, el GIAL irrumpía con unos resultados por encima de los previstos por el candidato popular.

"Y sacó cinco concejales que es un éxito para un partido independiente muy importante por encima de cualquier otro partido independiente y por encima de los resultados incluso de Izquierda Unida o del PA que ha podido tener en Almería". Fuente: entrevista a Rodríguez-Comendador.

En este nuevo campo político, el GIAL contaba con la llave si el Partido Popular quería obtener la alcaldía. Finalmente, se produjo la coalición entre el PP y GIAL, incorporando el líder de este último partido un estilo "facilitador", que le llevaba a adaptarse a las nuevas circunstancias, para ocupar el poder local en cohabitación con su anterior partido. En otras localidades de Almería, el GIAL obtuvo representación, llegando incluso a contar con un alcalde electo en Senés.

"Creamos ese grupo y determinó que como consecuencia de esos resultados ningún partido obtenía mayoría absoluta y llegamos a un pacto con el Partido Popular. No recordando las siglas donde yo he militado, sencillamente que era el partido que más coincidía con las ideas políticas que profesaba el GIAL en donde 
predominaba esa ideología liberal-conservadora que yo le mencionaba. Y en ese sentido empezamos a trabajar y yo creo que fue una corporación la del dos mil tres al dos mil siete muy rica". Fuente: entrevista a Megino.

En la práctica, la escisión entre el PP y el GIAL, no dejaba de evidenciar una pugna entre dos líderes de la derecha almeriense, creando una fractura en el campo político del PP almeriense y produciendo una redistribución de las posiciones jerárquicas y del poder local de dicha derecha. El proyecto político de Megino, que había obtenido un éxito considerable dadas sus posibilidades electorales, le otorgaba capacidad de chantaje, y también de negociación, frente a Rodríguez-Comendador, quien se veía obligado a pactar con Megino para formar gobierno y ser investido como alcalde. Finalmente, los dos grupos formaron una comisión de tres representantes de cada uno de ellos, que se encargó de fundir sus respectivos programas electorales en un único programa de gobierno. Pese a que ambos partidos tenían la misma ideología y un enfoque político similares, su pugna se producía entre dos personalidades y, por tanto, entre dos liderazgos. Megino no había sido un disciplinado político popular que debería haber aceptado su ascenso hacia el nivel de gobierno central, sino que se había rebelado y reivindicado en el ámbito local al coste que fuera. Esta alianza que era necesaria y podría entenderse como coherente, en realidad representó una coalición incómoda para Megino y Rodríguez-Comendador.

"Se negoció bien al final. Ellos (el GIAL) sacaron, pues todo lo que pusieron encima de la mesa y bueno funcionó razonablemente pues, con algún chirrido lógicamente porque fue un matrimonio de conveniencia, no por amor evidentemente. Y los matrimonios de conveniencia pues tienen eso". Fuente: entrevista a Rodríguez-Comendador.

Entre 2003 y 2011 , el GIAL se convirtió en una fuerza política fundamental en la ciudad de Almería, ya que el PP se tuvo que apoyar durante dos mandatos en esta formación para garantizar la alcaldía. Durante esos años, Megino procuró alguna de las áreas más estratégicas, tales como urbanismo, para su grupo político y se implicó personalmente, gracias a su posición en el gobierno local, en los Juegos Mediterráneos de Almería de 2005. Un proyecto por el cual había sentido un gran deseo de liderar y formar parte de él, algo con lo que rivalizaba con el mismo alcalde.

"De tal manera que, con cinco concejales, entonces el Partido Popular tenía once. El área, un área fundamental que, que tuvo GIAL fue justamente Urbanismo en un momento que se estaba desarrollando el gran "boom", ¿no? Y todavía me permitió, como consecuencia de esos pactos políticos, presidir el comité organizador de los Juegos Mediterráneos, una cuestión absolutamente querida por mí". Fuente: entrevista a Megino.

Al aproximarse las elecciones municipales de 2011, Megino decidió no concurrir como candidato. Intentó encontrar algún compañero de filas que siguiese con el GIAL. Siendo un partido tan centrado en su persona, no fue posible renovar su liderazgo. Por lo tanto, los cargos orgánicos y los miembros del GIAL decidieron reintegrarse en el Partido Popular. Esta decisión no estuvo exenta de polémica, ya que algunos de los antiguos miembros del GIAL se reincorporaron posteriormente en otros partidos de centro y centro-derecha como Ciudadanos.

"Ya en el dos mil, dos mil diez, eh, decidí ya que mi tiempo político ya estaba cumplido. No en vano, empecé en el noventa y uno, que habían sido veinte años de actividad intensa, pues decidí que ya no me iba a presentar a una nueva elección dentro de GIAL. Entonces busqué la posibilidad de que alguien pudiera continuar 
con esa, con esa llama, pero desgraciadamente nadie, nadie tiró de la misma".

Fuente: entrevista a Megino.

En torno a estas fechas, Megino abandonaba la política, sin que se hayan apreciado otros cargos de representación que pudiesen indicar el inicio de una carrera ascendente y/o multinivel alejada de la política local. De esta forma, finalizaba una experiencia de ocho años que consiguió dividir en dos almas a la derecha almeriense, basado en un estilo de liderazgo "facilitador".

\section{Conclusiones}

En este artículo se ha presentado cómo un líder político local se hace a sí mismo a través de su pensamiento, sus acciones y su discurso que son elementos elaborados intersubjetivamente entre sus seguidores y él mismo. Sin embargo, no se debe olvidar que buena parte de los recursos políticos de Megino procedían de un proceso de personalización, cooptación y apropiación de los que ya originariamente tenía el PP en Almería. En este caso, Megino comenzó como un médico profesional de ideología conservadora y un deseo de participar políticamente, habiendo sido educado en el entorno de una familia rural de clase media. Durante el tránsito de su socialización política acumuló diversos recursos políticos a través de cargos de representación en colectivos sindicales y profesionales. Megino no disponía de una afiliación política ni una experiencia partidista previa, lo que le situaba como un profesional liberal que podía ser integrado en las estructuras de cualquier partido de centro-derecha o derecha política. Esta situación coincidió contextualmente con la organización del Partido Popular en Almería a finales de los ochenta, cuando esta fuerza se había convertido en un catch-all-party y había moderado sus posturas con respecto a sus comienzos. De ahí, que este actor político tuviese una ventana de oportunidad para asumir responsabilidades como candidato y representante entre los populares, a través de su amistad con el cabeza de lista en las elecciones municipales de 1991, Fernando Cabezón. No obstante, su militancia es posterior a su elección como concejal, habiéndose presentado previamente como independiente en la lista para las elecciones municipales. Después, los distintos cambios y/o la inestabilidad estructural del grupo municipal del que formó parte entre 1991 y 1995 le benefició, permitiendo que se alzara como cabeza de lista en los siguientes comicios, llegando a convertirse en alcalde durante un mandato. Es en esta etapa donde se forjó su perfil político de corte municipalista y, por tanto, enfocado al gobierno local como "jefe de la ciudad". Aunque este perfil municipalista está relacionado con su deseo personal de compatibilizar su trabajo como médico con su liderazgo político, lo cual no podía hacer con tanta facilidad en caso de conseguir un cargo de representación autonómico y/o nacional. Megino quería ser alcalde y médico, o al menos no abandonar su carrera sanitaria por la política. La posible consolidación de su liderazgo local se vio truncada por la coalición de izquierdas que otorgó la presidencia local a Santiago Martínez (PSOE) entre 1999 y 2003. Así finalizaba su recorrido como líder político local desde un punto de vista institucional.

Pese a ello, la acumulación de cargos de representación, su reputación interna y su popularidad local le mantuvieron como un líder dentro de la arena política de los populares. Cuando la dirección de su partido intentó sustituirlo como candidato a la alcaldía en las elecciones de 2003, se produjo una fractura entre Rodríguez-Comendador y él mismo por convertirse en los líderes locales de la derecha almeriense. Aunque el primero contaba con el beneplácito oficial de la ejecutiva y había sido reconocido como candidato, la pugna se trasladaba al plano más social y simbólico de 
la política. Ello llevó a que Megino cooptase parte de sus seguidores en el seno del PP, apoyándose en distintos resortes de la sociedad civil, y crease un partido político conservador en torno a su figura: el Grupo Independiente por Almería. En esta nueva situación, Megino incorporó un estilo de liderazgo "facilitador" que le llevó a mantener una importante cuota de poder local.

A la luz de estos hallazgos, el apoyo político de Megino dependía tanto de su propio equipo como de parte de la comunidad local por su reputación como profesional sanitario. Ahora bien, al tratarse de un liderazgo político centrado en su persona y "facilitador" es complicado determinar hasta qué punto sus fuentes de poder dependían más de sus vínculos con agentes determinados del PP que le habían conocido personalmente, o de fuera del mismo partido. Según lo aquí argumentado, Megino se situaría más cercano a un líder local, con su fuente de poder sustentada en la estructura partidista, ya que en caso de que se hubiese apoyado más en la comunidad local no se habría producido la reintegración de los miembros del GIAL en el PP y un sector que más tarde se ha reincorporado en fuerzas como Ciudadanos (C's), tras la retirada de su candidatura a la alcaldía almeriense para las elecciones de 2011. Este retorno de los seguidores de Megino al PP es una evidencia de que la fuente de poder primigenia se situaba dentro del partido atrápalo-todo conservador y no en espacios sociales externos al mismo. Por tanto, sus fuentes de poder siempre fueron las mismas y estaban basadas principalmente en el poder político de la estructura del PP, tanto durante su etapa como alcalde como durante su tiempo como líder del GIAL. No hubo una auténtica evolución en sus capitales políticos que simplemente dejaron de ser de un proyecto político para pasar posteriormente a otro, a excepción de su reputación personal, su fama y su propio capital social.

La naturaleza del GIAL fue la de un partido conservador, de carácter local y eminentemente personalista en torno a la figura de un notable de la sociedad civil, Juan Megino. De ahí que este partido como fuerza política perviviese en tanto se mantuviera el liderazgo de su fundador. En calidad de grupo municipal dentro del Ayuntamiento de Almería funcionó como un actor con capacidad de chantaje, y de negociación; ello le sirvió como dispositivo de poder y formó coalición con el Partido Popular, para investir de alcalde a Luis Rogelio Rodríguez-Comendador en sus dos primeros mandatos. De esta forma, PP y GIAL formaron una genuina alianza en la que, aun existiendo divergencias personales entre sus líderes, se vieron obligados a entenderse para compartir el poder municipal. Incómodos viajeros de travesía política que convivieron mientras se mantuvo el liderazgo "facilitador" de Megino al frente de su partido.

Este caso aislado y minoritario permite demostrar cómo un actor situado en una posición estratégica en el interior de un campo político puede no sólo producir una fractura partidista, sino crear un nuevo escenario como resultado de sus acciones y pensamientos en el que él mismo mantiene la máxima posición jerárquica. Sin embargo, la contrapartida de ello es que no exista movilidad dentro de este campo apropiado por un actor político y que, tarde o temprano, este espacio político fracturado vuelva a recomponerse e integrarse en su estado anterior a la ruptura. Por tanto, el GIAL puede considerarse como "lista independiente" dentro de la clasificación de partidos de ámbito local que propone Ureta. Ahora bien, sus estrechos lazos con el PP y el resultado de ser un independiente a partir de la pugna por la reelección en el partido convencional o de ámbito estatal (PP), lo clasifican como un líder "independiente revelado" entre los perfiles de líderes de partidos independientes (Ureta, 2018: 14) 


\section{Bibliografía}

Aguiar, F. y Espinosa, E. (2011). Identidad andaluza y realidad nacional. Córdoba: Instituto de Estudios Sociales Avanzados.

Aurioles, J. y Manzanera, E. (2004). Economía y sociedad andaluza: análisis avanzado de las causas del desarrollo relativo. Sevilla: Centro de Estudios Andaluces.

Bäck, H.; Heinelt, H. y Magnier, A. (2006). The European Mayor: Political Leaders in the Changing Context of Local Democracy. Berlín: Springer.

Blondel, J. (1987). Political Leadership. Towards a General Analysis. Londres: Sage.

Blondel, J. y Thiébault, J.-L. (2010). Political Leadership, Parties and Citizens. Londres y Nueva York: Routledge.

Botella, J. (1992). La galaxia local en el sistema político español. Revista de Estudios Políticos, núm. 76, págs. 145-160.

Briquet, J.-L. (1997). La tradition en mouvement. Clientélisme et politique en Corse. París: Belin

Brown, A. (2018). El mito del líder fuerte. Liderazgo político en la Edad Moderna. Madrid: Círculo de Tiza.

Brugué, Q. (2002). Nuevos Ayuntamientos, concejales diferentes: del gobierno de las instituciones al gobierno de las redes. Revista Española de Ciencia Política, 7: 9-37.

Burns, J.M. (2010). Leadership. Nueva York: Harper Collins.

Camarero, M. (2009). La medición del capital social: el producto interior bruto social andaluz, español y europeo. En A. Jaime Castillo (Ed.), La sociedad andaluza del siglo XXI: diversidad y cambio (p. 89-114). Sevilla: Centro de Estudios Andaluces.

Capo, J. (1992). La élite política local en España. Revista de Estudios Políticos, núm. 76, págs. 127-143.

Cazorla, J. y Delgado, M. (1993). Factores de la estructura socioeconómica de Andalucía oriental. Granada: Universidad de Granada.

Combes, H. (2018). Trabajo político territorial y (auto)clasificaciones del quehacer político. Perspectiva desde la trayectoria de un líder barrial en la Ciudad de México. Íconos. Revista de Ciencias Sociales, 60, págs. 31-56. DOI: https://doi.org/10.17141/ iconos.60.2018.2823

Collado-Campaña, F. (2018). Liderazgo y estrategias políticas locales: los alcaldes de las capitales de provincia andaluzas (1979-2011). Sevilla: Universidad Pablo de Olavide, Tesis Doctoral.

Collado-Campaña, F. (2017). Una aproximación teórica al liderazgo político de los alcaldes en el sistema local de España. GIGAPP Estudios Working Papers, núm. 65, págs. 179-195.

Collado-Campaña, F., Jiménez-Díaz, J.F., y Entrena-Durán, F. (2016). El liderazgo político en las democracias representativas: propuesta de análisis desde el constructivismo estructuralista. Revista Mexicana de Ciencias Políticas y Sociales, núm. 61(228), págs. 57-90. DOI: http://dx.doi.org/10.1016/S0185-1918(16)30040-X

Coller, X. (2014). Factoría de ideas: Perspectivas sobre la identidad andaluza.Sevilla: Centro de Estudios Andaluces. 
Elgie, R. (2015). Studying Political Leadership: Foundations and Contending Accounts. Londres: Palgrave Macmillan.

Entrena-Durán, F. (2001). Modernidad y cambio social. Madrid: Trotta.

Entrena-Durán, F. y Jiménez-Díaz, J.F. (2014). Valores y estrategias de los agricultores familiares de invernadero del sudeste andaluz. Revista Española de Investigaciones Sociológicas, núm. 147, págs. 21-52. DOI: http://dx.doi.org/10.5477/cis/reis.147.21

Fernández, M. (2014). La culminación de la transición local en Almería: las elecciones municipales de 1983. Historia Actual Online, núm. 45, págs. 89-102.

Ferraro, F.J. y Aznar, J.A. (2008). El distrito agroindustrial de Almería: un caso atípico. Mediterráneo económico, núm. 13, págs. 353-382.

Flanagan, M. (2004). Mayors and the Challenge of Urban Leadership. Maryland: University Press of America.

Godmer, L. y Marrel, G. (2017). La politique au quotidien: L'agenda et l'emploi du temps d'une femme politique. Lyon: ENS éditions.

Inglehart, R. (2001). Modernización y posmodernización. El cambio cultural, económico y político en 43 sociedades. Madrid: Centro de Investigaciones Sociológicas.

Instituto de Estadística y Cartografía de Andalucía (2018). Andalucía pueblo a pueblo. Fichas municipales: Almería. Sevilla: Instituto de Estadística y Cartografía de Andalucía. https://www.juntadeandalucia.es/institutodeestadisticaycartografia/sima/ficha. htm?mun=04013 (último acceso: 09/02/2019).

Instituto Nacional de Estadística (2011a). Indicadores sociales: Educación. Edición 2011. Madrid: INE

(2011b). Indicadores sociales: Cultura. Edición 2011. Madrid: INE. https://www.ine.es/ dyngs/INEbase/es/operacion.htm?c=Estadistica_C\&cid=1254736176825\&menu=res ultados\&idp=1254735576508 (último acceso: 09/02/2019).

Jiménez-Díaz, J.F. (2018). La ética política en Max Weber: contexto, análisis e interpretación. Perseitas, vol. 6, núm. 1, págs. 99-122. DOI: https://doi.org/10.21501/ issn.2346-1780

Jiménez-Díaz, J.F. (2014). Inmigración marroquí y mercado de trabajo en la comarca del Poniente Almeriense. Provincia de Almería. En Nieves Ortega-Pérez (Ed.): Marroquíes en el mercado de trabajo andaluz: Almería, Cádiz y Huelva, Granada: Editorial Universidad de Granada, pp. 55-78.

Jiménez-Díaz, J.F. (2010). Relatos biográficos de agricultores. Memoria de la revolución agrícola en la costa de Almería y Granada. Granada: Comares.

John, P. y Cole, A. (1999). Political Leadership in the New Urban Governance: Britain and France Compared. Local Government Studies, vol. 25, núm. 4, págs. 98-115.

Joignant, A. (2012). Habitus, campo y capital. Elementos para una teoría general del capital político. Revista Mexicana de Sociología, vol. 74, núm. 4, págs. 587-618.

Kellerman, B. (2012). The end of Leadership. Nueva York: Harper Collins.

Leland, S. y Thurmaier, K. (2004). Case Studies of City-County Consolidation: Reshaping the Local Government Landscape. United States: M.E. Sharpe. 
Magre, J. y Bertrana, X. (2005). Municipal Presidentialism and Democratic Consolidation in Spain. En R. Berg y N. Rao (eds.), Transforming Local Political Leadership (p. 7384). Hampshire: Palgrave.

Márquez, G. (2007). Política y gobierno local: la formación de gobierno en las Entidades locales en España. Madrid: Centro de Estudios Políticos y Constitucionales.

Márquez, G. (1981). Almería en la transición: elecciones y sistemas de partidos (19761980). Almería: Guillermo Márquez.

Mabileau, A. (1972). Les facteurs locaux de la vie politique nationale. París: Pedone.

Martínez, G. y Ortega, C. (2010). Las elecciones municipales del 2007 en Andalucía. Psicología política, núm. 41 , págs. 7-25.

Mattina, C. (2016). Clientélismes urbains. Gouvernement et hégémonie politique à Marseille. París: Les Presses de Sciences Po.

Martínez, J.B. (2015). Los partidos políticos en el ámbito local en España. Estudio cuantitativo de la legislatura 2011-2015. En XII Congreso de la Asociación Española de Ciencia Política y de la Administración. Asociación Española de Ciencia Política y de la Administración, Murcia.

Natera, A. (1999). Percepciones y estilos de liderazgo local en la España democrática. Madrid: Universidad Complutense de Madrid.

Navarro, C. y Sanz, A. (2018). The social base and career development of Spanish Mayors. Revista Española de Ciencia Política, núm. 46, págs. 21-48. DOI: https://doi. org/10.21308/recp.46.02

Rahat, G. y Kening, O. (2018). From Party Politcs to Personalized Politics? Party Change and Political Personalization in Democracies. Oxford: Oxford University Press.

Reif, K. y Schmitt, H. (1997). Second order elections. European Journal of Political Research, vol. 31, issue 1-2, págs. 109-124. DOI: https://doi.org/10.1111/j.1475-6765.1997. tb00768.x

Reif, K. y Schmitt, H. (1980). Nine second-order national elections: a conceptual framework for the analysis of European election results. European Journal of Political Research, vol. 8, issue 1, págs. 3-44. DOI: https://doi.org/10.1111/j.1475-6765.1980.tb00737.x

Ruiloba, J.M. (2017). Género y liderazgo político: una revisión crítica. En D.C. FernándezMatos (Ed.), Liderazgo y participación política de las mujeres en América Latina en el siglo XXI (p. 21-43). Barranquilla y Cúcuta: Universidad Simón Bolívar.

Ruiloba, J.M. (2009). Géneros y estilos de liderazgo en el gobierno local: las alcaldesas en España. Madrid: Universidad Autónoma de Madrid.

Stolz, K. (2003). Moving Up, Moving Down: Political careers across Territorial Levels. European Journal of Political Research, vol. 42, issue 2, págs. 223-248. DOI: https://doi. org/10.1111/1475-6765.00081

Ubasart, G. (2012). Municipalismo alternativo y popular. ¿Hacia una consolidación de las tesis del nuevo localismo y la politización del mundo local? Revista de Estudios Políticos, núm. 157, págs. 135-162.

Ureta, M. (2018). Herramientas teóricas para la definición y análisis de las "candidaturas independientes" locales: nuevas posibilidades de estudio en el ámbito municipal. 
Revista de Investigaciones Políticas y Sociológicas, vol. 17, núm. 2, págs. 11-28. DOI: http://dx.doi.org/10.15304/rips.17.2.4489

Weber, M. (1993). El político y el científico. Madrid: Alianza.

Yates, D. (1977). The Ungovernable City: The Politics of Urban Problems and Policy Making. Cambridge: MIT Press. 